\title{
Sperm morphology in relation to semen cation concentration in Yankasa rams
}

${ }^{*}$ Suleiman, I. O., ${ }^{1}$ Raji, A.Y. and ${ }^{2}$ Atanda, A. O.

${ }^{1}$ Department of Animal Science, Bayero University Kano

${ }^{2}$ Department of Animal Science, Ahmadu Bello University, Zaria

*Corresponding author: ibro172000@yahoo.com; 08030520867

\section{Abstract}

The morphological appearance of sperm cells is a major criterion in semen evaluation. The optimal production of semen of high biological value is influenced by numerous factors. Therefore, a study was conducted to evaluate the relationship between sperm morphological characteristics and semen cation concentrations in 62 rams of Yankasa breed of sheep. Semen samples were collected from each animal on weekly basis for 52 weeks with electroejaculator. The sperm morphological characteristics examined were: detached mid-piece and tail (DMT), detached head (DH), mid-piece droplet (MPD, coiled and bent tail (CBT) and acrosomal abnormality (ACR). The semen cation parameters measured were: sodium ion $\left(\mathrm{Na}^{+}\right)$, potassium ion $\left(\mathrm{K}^{+}\right)$and calcium ion $\left(\mathrm{Ca}^{2+}\right)$. Pearson correlation matrix of SAS was used to determine the relationships among and between the measured characteristics. The result of the study showed that correlations among the sperm morphological characteristics were low and not significant except that between DH and DMT which was perfect $(p<0.01 ; r$ $=1.00)$. On the other hand, semen cation concentrations were positively correlated but not significant among themselves except the correlation between $\mathrm{Na}^{+}$and $\mathrm{K}^{+}(p<0.01 ; r=0.37)$ which was significant. Relating the semen cation concentration with sperm morphological characteristics, it was discovered that potassium ion $\left(K^{+}\right)$measured was negatively and significantly correlated with all the morphological attributes (DMT \& DH, r=-0.36@ $p<0.01 ; C B T \& A C R, r=-0.38 @ p<0.05 ; M P D, r=-0.32 @ p<0.05)$. It was concluded that $\mathrm{DH}$ is highly associated with DMT while $\mathrm{Na}^{+}$concentration was an indicator for $\mathrm{K}^{+}$level in the semen as shown in the result. Also, the higher the potassium ion in semen, the lower the level of sperm morphological abnormalities and vice versa in Yankasa rams.

Keywords: Sperm morphological characteristics, semen cation concentrations, Yankasa rams

\section{Introduction}

The morphological appearance of sperm cells is a major criterion in semen evaluation. It is the most important qualitative characteristics of semen (Kuster et al., 2004). It is the basic indicator for predicting the fertilizing ability of spermatozoa, based upon correlation between particular categories of spermatozoa and fertility results (LucasZewiez, 1998). Examination of sperm morphology and determination of number of spermatozoa with morphological defects play a significant role in semen quality assessment, thus enabling the elimination of males with potentially low fertility prior to the preservation of their semen (Rodriguez-Martinez and Barth, 2006). Among the reproductive traits, quality semen plays a major role in determining the fertility and reproductive efficiency of any livestock production. The optimal production of semen of high biological value is influenced by numerous factors, including: breed (Kondracki et al., 2007; Smital et al., 2004), season of the year (Ciereszko et al., 2000; Wysokinska et al., 2005), age of the animal, and frequency of sperm collection (Deka et al., 2002). Primary abnormalities originated in the testis during spermatogenesis during the development of the testicular tubules while 


\section{Sperm morphology in relation to semen cation concentration in Yankasa rams}

secondary abnormalities originated in the epididymis due to changes taking place during storage in the epididymis. Tertiary abnormalities are those arising from poor handling techniques (Rao and Rao, 1980). Semen volume, sperm motility and sperm concentration have been reported to be negatively correlated with abnormal spermatozoa in Yankasa rams (Suleiman and Adu, 2012a; Akpa et al., 2012a and Akpa et al., 2012b). Reddy et al. (1975) also reported significant negative correlation between abnormal spermatozoa and conception rate.

Cation concentrations in the seminal plasma provide the congenial milieu for the survival of sperms (Kalita et al., 2006). The concentrations of different ions in seminal plasma also reflect the quality of semen and physiological status of reproductive accessory gland (Kalita et al., 2006). Calcium is important for semen physiology including motility and glycolysis (Morton et al., 1987), metabolism (Peterson and Freund, 1976), acrosome reaction and fertility (Yanagimachi, 1981). Sodium is an extracellular element while potassium is intracellular in nature. Therefore, the objective of this study was to determine the relationships between sperm morphological characteristics and semen cation concentrations in Yankasa rams.

\section{Materials and methods \\ Studylocation}

The study was conducted at the Experimental and Research Farm of the Department of Animal Science, Ahmadu Bello University, Zaria located within the northern Guinea savanna between latitude $11^{\circ}$ and $12^{\circ} \mathrm{N}$ and on altitude of $640 \mathrm{~m}$ above sea level (Akpa et al., 2002). The area has two seasons; dry season (November to April) and rainy season (May to October). An average annual maximum temperature of $33.17 \pm 0.67^{\circ} \mathrm{C}$ and $18.74 \pm 0.63^{\circ} \mathrm{C}$ characterize the climate of the area.

Experimental animals and management

A total number of 62 Yankasa rams were used for the study. The animals were under the management of the Department of Animal Science, Ahmadu Bello University, Zaria at semi-intensive level of production. They were subjected to dipping against ectoparasite as well as anti-helminthis through drenching (deworming) and vaccination against endemic diseases. The rams were at three age categories; 12-18, 19-24 and 25-36 months.

\section{Semen collection and evaluation}

Semen samples were collected from 62 rams using electro-ejaculator and labelled accordingly. These were taken on weekly basis for 52 weeks of the experiment. Smear of each semen sample was prepared, airdried and labelled to examine sperm morphological abnormalities. After cleaning the smeared slides with oil immersion, they were placed on electronic microscope and the total number of abnormal cells were counted using hemocytometer and recorded. Types of abnormalities observed were detached midpiece and tail (DMT), detached head (DH), mid-piece droplet (MPD), coiled or bent tail (CBT) and acrosome (ACR) (acrosome membrane detached, acrosome outline and acrosome cap defect). The remaining semen samples were immediately taken to Pathological Department of ABU Teaching Hospital for mineral analysis where Coleman 21 Flame Photometer was used for mineral analysis. The cation analyzed were Calcium $\left(\mathrm{Ca}^{2+}\right)$, Sodium $\left(\mathrm{Na}^{+}\right)$, Potassium $\left(\mathrm{K}^{+}\right)$and Phosphate ions $\left(\mathrm{PO}_{4}\right)$.

\section{Data analysis}

Correlation analysis procedure (Pearson correlation) of SAS (2002) was used to assess the relationship between the semen abnormalities and semen cation concentration. 


\section{Suleiman, Raji and Atanda}

\section{Results and discussion}

The result of the relationship among sperm morphological characteristics is presented in Table 1. The relationship was generally low and not significant, except between DH and DMT which may have indicated perfect relationship $(\mathrm{P}<0.01 ; \mathrm{r}=1.00)$. This signifies that all the abnormal spermatozoa showing DMT have a corresponding DH in the semen samples. The CBT was negatively related to other abnormalities but not significant. These results are in agreement with Ambali et al. (2018) who also reported perfect relationship in the same attributes in Red Sokoto bucks and Cevik et al. (2007) who reported $\mathrm{r}=0.45$ in bulls.

Table 1: Correlation coefficients (r) among sperm morphological traits in Yankasa rams

\begin{tabular}{lllll}
\hline Traits & MPD & DH & CBT & ACR \\
\hline DMT & 0.02 & $1.00^{*}$ & 0.20 & 0.13 \\
MPD & & 0.20 & 0.09 & 0.04 \\
DH & & 0.20 & 0.13 \\
CBR & & & & 0.08 \\
\hline
\end{tabular}

DMT - Detached Midpiece and Tail, MPD - Midpiece Droplet, DH - Detached Head, CBT - Coiled and Bent Tail, ACR - Acrosome (all at $\left.\times 10^{6}\right)$. $* *-p<0.01$.

Table 2 shows the result of the relationship among semen cation concentrations. The relationships were positive but nonsignificant except the relationship between sodium ion and potassium ion $(r=0.37$; $\mathrm{P}<0.01)$ which was significant. The moderate, positive and significant relationship between the two ions may confirm their responsibility in maintaining osmolarity and metabolic activities of the spermatozoa in seminal fluid. This assertion agrees with Ambali et al. (2018) who reported $\mathrm{r}=0.30$ in Red Sokoto bucks and Quinn et al. (1965) who reported $\mathrm{r}=0.51$ in their study on the distribution of the major cations in semen and male accessory secretions. Nath (1988) also reported a positive and significant relationship between the two ions in buffalo semen.

Table 2: Correlation coefficients (r) among semen cation concentration in Yankasa rams

\begin{tabular}{llll}
\hline Cation & Potassium ion & Calcium ion & Phosphate ion \\
\hline Sodium ion & $0.37^{* *}$ & 0.07 & 0.14 \\
Potassium ion & & 0.12 & 0.02 \\
Calcium ion & & & 0.02 \\
\hline ** - $<\mathbf{0 . 0 1}$ & & &
\end{tabular}

The result of the relationship between sperm morphological characteristics and semen cation concentration is presented in Table 3 . In the result, only potassium ion had a negative and significant relationship with sperm abnormalities ranged between 0.32 to -0.38 . This is an indication that an increase in potassium ion in the seminal fluid will result into a corresponding decrease in the occurrence of sperm defect in the rams. The result is in consonance with the reports of Nath, (1988) on buffalo semen in India, Akpa et al. (2013) on semen from Red Sokoto bucks in northern Nigeria and Ambali et al. (2018) who reported the relationships between similar variables in Capra aegagrus hircus. 
Sperm morphology in relation to semen cation concentration in Yankasa rams

Table 3: Correlation coefficients ( $r$ ) between sperm morphology and semen cations concentration in Yankasa rams

\begin{tabular}{llllll}
\hline Cation/morphology & DMT & MPD & DH & CBT & ACR \\
\hline Sodium ion & 0.40 & 0.06 & 0.04 & 0.11 & 0.09 \\
Potassium ion & $0.36^{* *}$ & $0.32^{* *}$ & $0.36^{* *}$ & $0.38^{*}$ & $0.38^{*}$ \\
Calcium ion & 0.08 & 0.01 & 0.08 & 0.05 & 0.11 \\
Phosphate ion & 0.13 & 0.10 & 0.13 & 0.32 & 0.05 \\
\hline
\end{tabular}

** - p <0.01. * - p $<0.05$. DMT - Detached Midpiece \& Tail, MPD - Midpiece Droplet, DH - Detached Head, CBT - Coiled \& Bent Tail, ACR - Acrosome (all at $\left.\times 10^{6}\right)$.

\section{Conclusions}

The study showed that with the knowledge of cation concentration in semen, it is possible to determine the amount of sperm morphological abnormalities inherent in them. The report of this study could be applied in animal reproduction and breeding most especially as a guide to selection in order to give a desired selection response and appropriate genetic gain from selection.

\section{References}

Akpa, G. N., Ifut, O. J. and Mohammed, F. 2002. Indigenous management of Dystocia in ruminant livestock of Northern guinea savanna of Nigeria. Nigerian Journal of Animal Production, 29(2): 264-270

Akpa, G. N., Suleiman, I. O. and Alphonsus, C. 2012a Relationship between Body and Scrotal Measurements, and Seminal Characteristics in Yankasa Rams. Continental Journal of Animal and Veterinary Research 4(1): 7-10. $I S S N=2141-405 X$. www.wiloludjournal.com

Akpa, G. N., Suleiman, I. O., Alphonsus, C. and Adu, O.A. 2012b. Variation of Age, Hair Type and Condition Score with Sperm Morphology and Cation Concentration in Yankasa Rams. Elixir Journal of Applied Biology (47) 8629-8632. ISSN = $\begin{array}{llllllllll}2 & 2 & 2 & 9 & - & 7 & 1 & 2 & X\end{array}$. http://www.elixirjournal.org
Akpa, G. N., Ambali, A. L. and Suleiman, I. O. 2013b. Relationships between Semen cation Concentration, Semen Characteristics, Testicular Measurements and Body Conformation Traits in Red Sokoto Goats. Nature and Science 2013: 11(7): 94-99. ISSN 1545-0740 http://www.sciencepub.net/nature.

Ambali, A. L., Anoh K. U. and Suleiman I. O. 2018. Relationships between Sperm Morphology and Semen Cation Concentrations in Red Sokoto Goats (Capra aegagrus hircus). International Journal of Livestock Production, 9(6): 108111. I S S N 2141-2448. http:www.academicjournals.org/I $J L P$

Cevik, M., Tuncer, P. B., Tasdemir, U. and Ozgurtas, T. 2007. Comparison of spermatological characteristics and biochemical seminal plasma parameters of Norma-zoospermic and Oligoastheno-zoospermic Bulls of two Breeds. Turkish Journal of Veterinary \& Animal Sciences, 31(6):381-387.

Ciereszko, A., Ottobre, J. S. and Glogowski, J. 2000. Effects of season and breed on sperm acrosin activity and semen quality of boars. Animal Reproduction Science, 64: 89-96.

Deka, D., Goswami, R. N., Mili, D. C. and Nath, D. R. 2002. Effect of age of the sow and boar on reproduction 


\section{Suleiman, Raji and Atanda}

performance. Indian Veterinary Journal, 79: 615-616.

Kalita, D. J., Sarmah, B. C. and Goswami, S. 2006. Effect of mineral supplementation on seminal plasma of Assam local goat. Indian Journal of Applied Animal Research, 40(1): 162-165.

Kond racki，S., Wysokinska，A., Banaszewska, D. and Iwanina, M. 2007. Application of spermiogram classification for evaluation of the semen morphology of a boar or a group of boars (in Polish). Scientific Annals of Polish Society of Animal Production, 1(3): 79-89.

Kuster, C. E., Singer, R. S. and Althouse, G. C. 2004. Determining sample size for the morphological a s s e s ment of $\mathrm{sperm}$. Theriogenology 61: 691-703.

Lucas-Zewiez, E. 1998. Study of diluents for cock's semen storage in the light of laboratory estimation and fertility rates. Zeszyty Naukowe A.R, we. Wroclawiu, Zootechnika XXX 168, 43-59 (in Polish)

Morton, H. D., Harrigan-Lum, J. and Albagli, L. 1987. The activation of motility in quiescent hamster sperm from the epididymis by calcium and cyclic nucleotides. Biochemical Biophysical Resource Community, 56, 372-379.

Nath, R. 1988. Cryopreservation of buffalo semen. M.V.Sc. Thesis, Gobind Ballabh Pant University of Agriculture and Technology, Pantnagar, India.

Peterson, R. N. and Freund, M. 1976. Relationship between motility and the transport and binding of divalent cation to the plasma membrane of human spermatozoa. Fertility and Sterility, 27: 1301-
1307.

Quinn, P. J., White, I. G. and Wirrick, B. R. 1965. Studies of the distribution of the major cations in semen and male accessory secretions. Journal of Reproduction and Fertility, 10:379-388.

Rao, T. L. N. and Rao, A. R. 1980. Fertility and its relationship with semen characteristics in crossbred bulls. Indian Veterinary Journal 56: 3336

Reddy, V. S. C., Benzamin, B. R. and Sharma, B. S. 1975. Evaluation of sperm abnormalities in Murrah buffalo and its relationship with conception rate. Indian Journal of Animal Production, 6: 41-45.

Rodriguez-Martinez, H. and Barth, A. D. 2006. In-vitro evaluation of sperm quality related to in-vivo function and fertility. Society of Reproduction and Fertility Supplement, 64: 39-54.

SAS, 2002. Statistical Analysis System, Computer Software, and Version 9.0: SAS institute Inc. Cary, NC 27513, USA.

Smital, J., De Sousa, L. L. and Mohnsen, A. 2004. Differences among breeds and manifestation of heterosis in AI boar sperm output. Animal Reproduction Science, 80: 121-130.

Suleiman, I. O. and Adu, O.A. 2012a. The effect of Age, Hair Type and Condition Score on Testicular and Semen Characteristics in Yankasa Rams. Applied Tropical Agriculture 17 (1 \& 2): Pp 179186. ISSN = 1118-6712. http:www.appliedtropicalagricult ure.com

Wysokinska, A., Kondracki, S. and Banaszewska, D. 2005. The Influence of Season on the Semen 
Sperm morphology in relation to semen cation concentration in Yankasa rams

Quality of Duroc, Hampshire and Pietrain purebred boars and crossbreds of Duroc x Pietrain and Hampshire x Pietrain (in Polish). Scientific Annals of Polish Society of Animal Production, 1: 535-544.
Yanagimachi, R. 1981. Mechanisms of fertilization in mammals. In Mastroianna Jr, L., Biggers, J.D. (eds), Fertilization and Embryonic Development in-vitro. Plenum Press, New York, Pp88-182.

Received: $10^{\text {th }}$ April, 2019

Accepted: $25^{\text {th }}$ July, 2019 